\title{
La prensa estudiantil bajo dictadura. Apuntes para un estudio comparativo entre España y Argentina
}

\author{
Student Periodicals under Dictatorship. Notes for \\ a Comparative Study between Spain and Argentina
}

\author{
Guadalupe A. Seia* \\ CONICET \\ Instituto de Altos Estudio Sociales (UNSAM). Universidad de Buenos Aires
}

$\begin{array}{ll}\text { Recibido: } & 12 / 02 / 2020 \\ \text { Aceptado: } & 06 / 05 / 2020\end{array}$

DOI: https://doi.org/10.20318/cian.2020.5429

Resumen: En el presente artículo planteamos las primeras aproximaciones para un estudio comparativo de la prensa estudiantil bajo dictadura en España (1939-1975) y Argentina (1976-1983). A partir del estudio del caso de la Universidad de Buenos Aires, proponemos una caracterización general de las experiencias editoriales de los estudiantes universitarios en ambos países y algunas claves comparativas en relación con las modalidades en que surgieron y cómo se fueron reconfigurando dichos proyectos editoriales respecto de sus posturas hacia el régimen y del desarrollo del movimiento estudiantil de cada país.

Palabras clave: prensa estudiantil, universidad, dictadura, España, Argentina.
Abstract: This article seeks to contribute to comparative analysis of the student periodicals under dictatorship in Spain (19391975) and Argentina (1976-1983). Based on a case study about the student movement at the Universidad de Buenos Aires (University of Buenos Aires), we describe the editorial experiences of students in both countries. We develop comparative keys focusing on the modalities in which the student periodicals initiated and the process by they changed their positions towards the regime. Also, we explore the relationship between the student press and the student movement of each country.

Keywords: student periodicals, university, dictatorship, Spain, Argentina.

*guadalupeseia@gmail.com 


\section{Introducción ${ }^{1}$}

En el último lustro el campo de estudios sobre el movimiento estudiantil sudamericano durante los años de las dictaduras inspiradas en la Doctrina de Seguridad Nacional se ha expandido y consolidando ${ }^{2}$. El profuso trabajo de reconstrucción empírica ha cuestionado ideas cristalizadas acerca de la "muerte" del Movimiento Estudiantil latinoamericano producto de la represión sufrida y de los cambios acontecidos en los sistemas universitarios de cada país durante las décadas de 1970 y $1980^{3}$, dando cuenta de tempranos procesos de reorganización estudiantil que permitieron la conformación de un movimiento con diferentes niveles de protagonismo durante las transiciones democráticas. En el marco del desarrollo del trabajo de campo de dichas investigaciones, los y las cientistas sociales accedieron a un conjunto de documentos clave para reconstruir ese proceso: las revistas estudiantiles. $\mathrm{Su}$ centralidad fue tal que las publicaciones elaboradas por el alumnado universitario no sólo se constituyeron como fuente sino también como objeto de investigación. En concreto, la prensa estudiantil se constituyó como un espacio de socialización y politización fundamental para la reorganización del movimiento estudiantil universitario de las principales ciudades de Brasil, Chile, Uruguay y Argentina durante sus respectivas dictaduras ${ }^{4}$. En el caso argentino en particular, esta práctica estudiantil no era una novedad ${ }^{5}$ pero

${ }^{1}$ Agradecemos las observaciones realizadas en las revisiones ciegas, así como por parte del coordinador del presente dossier, Dr. Alberto Carrillo-Linares. Las hipótesis aquí planteadas corren enteramente por nuestra cuenta.

${ }^{2}$ Rodrigo Patto Sá Motta, Ditaduras militares. Brasil, Argentina, Chile e Uruguai, (Belo Horizonte: Editora UFMG, 2015).

${ }^{3}$ Joaquín Brunner, "El movimiento estudiantil ha muerto. Nacen los movimientos estudiantiles," Material de discusión FLACSO, n. 71 (1985): s/p.

${ }^{4}$ Angélica Müller, O movimiento estudiantil na Resistencia a ditadura militar (1969-1979) (Rio de Janeiro: Garamond, 2016); Diego García Monge, José Isla Madariaga y Pablo Toro Blanco, Los muchachos de antes. Historias de la FECH 1973-1988 (Santiago: Universidad Alberto Hurtado, 2006); Pablo Toro Blanco, "Entre la lana y el gel: notas sobre opciones y estilos artísticos y culturales del movimiento estudiantil en la Universidad de Chile (ca. 1977- ca. 1990),", en Movimientos estudiantiles en la historia de América Latina, ed. Renate Marsiske (México: UNAM, 2017); Gabriela González Vaillant, "Entre los intersticios de la democracia. Las revistas estudiantiles, la universidad uruguaya en transición y las pujas políticas por los significados de la democracia", Revista de Historia Social y de las Mentalidades, v.22, n. 2 (2018): 73-102.

${ }^{5}$ Las revistas constituyeron un espacio nodal para el desarrollo de la organización estudiantil durante las primeras décadas del siglo XX (Natalia Bustelo, "La Reforma Universitaria desde sus grupos y revistas: Una reconstrucción de los proyectos y las disputas del movimiento estudiantil porteño de las primeras décadas del siglo XX (1914-1928)." (Tesis doctoral, 
hemos dado cuenta de que se constituyó un fenómeno particularmente relevante en los años del autodenominado "Proceso de Reorganización Nacional" cuando las organizaciones políticas y gremiales del estudiantado fueron ilegalizadas y reprimidas ${ }^{6}$.

En el presente artículo presentamos las primeras consideraciones de una investigación en curso que se propone analizar comparativamente el papel de las revistas estudiantiles en el movimiento estudiantil bajo regímenes dictatoriales en Iberoamérica. En estas páginas focalizamos sobre las expresiones de la prensa estudiantil argentina entre 1976 y 1983 y española entre 1939 y 1975 bajo el régimen de Francisco Franco ${ }^{7}$. Antes de avanzar, vale considerar que, a pesar de la prolífica tarea de los campos de investigación sobre los movimientos estudiantiles en España y Argentina, aún no han sido exploradas las potencialidades que las investigaciones de tipo comparativas ofrecen $^{8}$, tal cual lo ilustra la tesis doctoral de Javiera Errazuriz Tagle quien compara el lugar y las transformaciones de los movimientos estudiantiles de Madrid y Santiago de Chile durante las transiciones democráticas en España y Chile.

A continuación, retomamos su propuesta para comenzar a delinear una agenda de investigación comparativa en clave global e iberoamericana a partir de los desarrollos del campo de la Historia Reciente del América del Sur que plantea el estudio sistemático de similitudes y diferencias entre dos o más fenómenos para contribuir en su mejor descripción, explicación e interpretación, posibilitando ver cómo determinados rasgos que están presentes en una

UNLP, 2015)). Aunque sin desaparecer, esta modalidad perdió centralidad en el proceso de organización el movimiento estudiantil argentino desde mediados del mismo siglo.

${ }^{6}$ Guadalupe Seia, "De la revolución a la reforma. Reconfiguraciones de las formas de militancia estudiantil en la Universidad de Buenos Aires entre 1976 y 1983" (Tesis de Doctorado, UBA, 2019).

${ }^{7}$ Una primera fase del trabajo de campo fue posible gracias a la generosidad del Dr. Alberto Carrillo-Linares quién dirigió la estancia de investigación postdoctoral realizada en la Universidad de Sevilla entre septiembre y noviembre de 2019 a partir de la Beca de Movilidad otorgada por la Asociación Universitaria Iberoamericana de Postgrado (AUIP).

${ }^{8}$ Para una perspectiva transnacional sobre los intercambios y redes de estudiantes universitarios iberoamericanos durante la primera mitad del siglo XX, véase: Luciana Carreño, "La Federación Universitaria Hispanoamericana en Madrid", CIAN-Revista de Historia de las Universidades, v. 16 n.1 (2013): 51-80; Laura Rodríguez, "Los estudiantes reformistas y su proyección latinoamericana: los congresos internacionales (1921-1957)," Revista del IICE, n. 44 (2018): 11-24.

${ }_{9}^{9}$ Javiera Errazuriz Tagle, "Movimiento estudiantil en el tránsito de dictadura a democracia. Madrid (1969-1980) y Santiago de Chile (1986-1997) en perspectiva comparada" (Tesis de Doctorado, UCC-UAM, 2013). 
experiencia se encuentran o no en otras ${ }^{10}$. La comparación histórica permite la construcción de problemas de investigación e hipótesis de trabajo que difícilmente surgirían al mirar un único caso; la identificación de particularidades de los casos analizados, reponiendo las carnaduras históricas de las experiencias y los procesos vividos en cada sociedad; la puesta en consideración de hipótesis de trabajo, potenciando el nivel analítico; también, la desprovincialización y desnaturalización de perspectivas y sentidos extendidos en el campo académico local; y por último posibilidad la visualización de interacciones antes no observadas sin perder de vista las particularidades nacionales ${ }^{11}$.

Para iniciar ese camino, en estas páginas, tomamos a la clave comparada como un lente de realce de las interpretaciones sobre un problema delimitado como el surgimiento y desarrollo de revistas estudiantiles bajo un régimen dictatorial desde la experiencia argentina que tomaremos como punto de partida. A partir de la investigación que hemos desarrollado sobre la principal universidad en Argentina, pondremos en juego ciertas hipótesis analíticas para pensar la experiencia española. Lejos de buscar, a través de la comparación, generalizaciones o teorizaciones sin sustento empírico, el objetivo es construir y complejizar las interpretaciones específicas sobre cada caso de estudio y a la vez, problematizar la especificidad de los procesos históricos.

Antes de avanzar, por último, resulta pertinente realizar algunas aclaraciones. Debemos precisar que el objeto de análisis de este texto es el fenómeno de las revistas estudiantiles en el marco del proceso de reorganización del movimiento estudiantil universitario bajo regímenes dictatoriales. Acordamos con Daniel Lvovich acerca de los límites para asemejar los regímenes que tuvieron lugar en Argentina entre 1976 y en España entre 1939 y $1975^{12}$.

\footnotetext{
${ }^{10}$ Ernesto Bohoslavsky, "Introducción al Dossier: América Latina (1950-1989): perspectivas desde la historia comparada", Quinto Sol, v. 19, n. 1 (2015): 1-3; Soledad Lastra, "La historia comparada y sus desafíos para interrogar el pasado reciente del Cono Sur," Revista de História Comparada, v.12, n. 2 (2018): 139-171.

${ }^{11}$ Heinz Haupt y Jürgen Kocka, "Comparison and Beyond: Traditions, Scope, and Perspectives of Comparative History", en Comparative and transnational history. Central European Approaches and New Perspectives, ed. Heinz Haupt y Jürgen Kocka (New York-Oxford: Bergham Book, 2009).

${ }^{12}$ El historiador identifica algunas similitudes ideológicas (conservadurismo, tradicionalismo, escasa voluntad movilizadora) y diferencias tales como la duración de los regímenes, sus formas institucionales, los grados de represión, la implicación de la Iglesia Católica, las circunstancias de origen, y el contexto histórico en que se desarrollaron (Daniel Lvovich, "Actitudes sociales y dictaduras: las historiografías española y argentina en perspectiva comparada," en Procesos represivos y actitudes sociales: entre la España franquista y las dictaduras del Cono Sur, ed. Gabriela Águila y Luciano Alonso (Buenos Aires: Prometeo, 2013)).
} 
Sin embargo, siguiendo los señalamientos realizados por Luciano Alonso acerca de la posibilidad de caracterizar (más allá de sus especificidades) a los regímenes acaecidos en Iberoamérica como "dictaduras regresivas" ${ }^{13}$, consideramos pertinente proponer interrogantes de tipo comparativo acerca del movimiento estudiantil, atendiendo ciertos rasgos compartidos respecto de los procesos de intervención, depuración y represión hacia las universidades estatales por parte de las dictaduras en cuestión ${ }^{14}$. En este sentido, la opción por la comparación atiende a este tipo de criterios sobre las variables cronológicas. De todos modos, las particularidades de los contextos históricos en que las revistas analizadas surgieron es un factor considerado en el análisis.

\section{Las revistas estudiantiles en Argentina (1976-1983)}

La actividad política estudiantil en las universidades argentinas durante la última dictadura ha sido escasamente analizada hasta la actualidad. En ese sentido, hasta el momento conocemos principalmente las revistas producidas por los y las estudiantes de la Universidad de Buenos Aires (UBA en adelante). Como mencionamos, la prensa de los estudiantes universitarios no fue una novedad de la etapa dictatorial. Sin embargo, en el marco de la prohibición de la actividad política y gremial ${ }^{15} \mathrm{y}$ el despliegue de las fuerzas

${ }^{13} \mathrm{El}$ autor afirma que los regímenes que tuvieron lugar en Portugal, España, Brasil, Chile, Uruguay y Argentina pueden ser descriptos como estados de excepción capitalistas con un carácter primordialmente contrarrevolucionario: "En la situación 'defensiva' del bloque de poder al que respondían, constituyeron la negación de los procesos de participación popular que vinieron a clausurar y sostuvieron la preeminencia social de clases sociales o fracciones de clase amenazadas (...)" (Luciano Alonso, "Dictaduras regresivas y represiones en Iberoamérica: trayectorias particulares y posibilidades de comparación," en Procesos represivos y actitudes sociales: entre la España franquista y las dictaduras del Cono Sur, ed. Gabriela Águila y Luciano Alonso (Buenos Aires: Prometeo, 2013)).

${ }^{14}$ Véase: Carolina Rodríguez López, "La universidad europea bajo las dictaduras", Ayer, n. 101 (2006); Carolina Rodríguez López, La Universidad de Madrid en el primer franquismo: ruptura y continuidad (1939-1951) (Madrid: Editorial Dykinson/Universidad Carlos III, 2002); Laura Rodríguez, Universidad, peronismo y dictadura. 1973-1983 (Buenos Aires: Prometeo, 2015); Pablo Buchbinder, "La Universidad de Buenos Aires bajo la dictadura. Una aproximación a través del estudio del perfil, discurso y pronunciamientos públicos de dos de sus rectores," CIAN-Revista de Historia de las Universidades, 19/2 (2016): 153-173.

${ }^{15}$ En la tradición del movimiento estudiantil argentino, los estudiantes se organizan colectivamente en agrupaciones con diferentes identidades político-ideológicas que además se nuclean en organismos gremiales conocidos como Centros de Estudiantes por facultad que coordinan su accionar en Federaciones por universidad y a nivel nacional. Véase, Mariano Millán y Guadalupe Seia, "El movimiento estudiantil como sujeto de conflicto social en Argentina 
represivas en las facultades ${ }^{16}$, la producción de revistas cobró una relevancia destacable. Dicha experiencia del alumnado universitario se inscribió en un fenómeno más amplio de producción editorial semi-clandestina durante la dictadura. Entre las llamadas revistas "subterráneas" se destacaron las del mundo cultural y musical, particularmente orientadas hacia la juventud ${ }^{17}$. Asimismo, los partidos de izquierda (ilegalizados o no) también buscaron canalizar sus posicionamientos a través de publicaciones periódicas orientadas a la población más joven ${ }^{18}$. En estas publicaciones, la vida universitaria ocupaba una sección permanente. En las escuelas secundarias también surgieron revistas producidas por los y las estudiantes ${ }^{19}$. Como podemos observar, por un lado, la producción editorial se vio potenciada ante las limitaciones concretas en el desarrollo público de actividades políticas. Por otro, las revistas estudiantiles no se constituyeron como una experiencia aislada ni peculiar del mundo universitario, sino que deben ser situadas en relación al campo de la cultura y las izquierdas.

\section{Desde abajo, primero, y desde arriba, luego}

Con relación a las afirmaciones previas y atendiendo al fenómeno editorial específicamente estudiantil es posible destacar algunos rasgos. En primer lugar, es menester precisar el protagonismo que las organizaciones políticas (específicamente sus ramas juveniles y universitarias) tuvieron en el surgimiento y el desarrollo de dichas publicaciones, en particular de las revistas estudiantiles. En efecto, para el surgimiento de las revistas de la UBA durante la dictadura, la iniciativa de los partidos políticos fue fundamental. Como se observa en el Cuadro 1, la Federación Juvenil Comunista impulsó revistas en las facultades de Ciencias Exactas y Naturales, Filosofía y Letras, Psicología

(1871-2019). Apuntes para una mirada de larga duración," Entramados y Perspectivas, v. 9, n. 9 (2019): 125-167.

${ }^{16}$ Seia, "De la revolución a la reforma": 92-104.

${ }^{17}$ Evangelina Margiolakis, "La conformación de una trama colectiva de publicaciones culturales subterráneas durante la última dictadura cívico-militar," Contenciosa, v. 2, n. 2 (2016): 1-13; Federico Iglesias, Escritores, dictadura y resistencia: un estudio sobre la revista El Ornitorrinco 1977-1983 (Los Polvorines: UNGS-UNLP-UNAM, 2019).

${ }^{18}$ Valeria Manzano, La era de la juventud, Cultura, política y sexualidad desde Perón hasta Videla, (Buenos Aires: FCE, 2017); Laura Luciani, Juventud en dictadura: representaciones, políticas y experiencias juveniles en Rosario: 1976-1983 (La Plata: UNLP-UNAM-UNGS, 2017).

${ }^{19}$ Rubén Berguier, Eduardo Hecker y Ariel Schifrin, Estudiantes secundarios: sociedad y política (Buenos Aires: CEAL, 1986). 
Cuadro 1. Revistas estudiantiles en la Universidad de Buenos Aires entre 1977 y 1983

\begin{tabular}{|c|c|c|c|}
\hline $\mathbf{N}^{\circ}$ & Título y editor & Fecha & Facultad \\
\hline 1 & $\begin{array}{l}\text { Arquitectura contra la dictadura. Juventud } \\
\text { Universitaria Peronista/Milicias Montoneras }\end{array}$ & 1977 & Arquitectura y urbanismo \\
\hline 2 & $\begin{array}{l}\text { Interacción. Impulsó: Federación Juvenil Comunista, } \\
\text { Partido Comunista Argentino (FJC-PCA) }\end{array}$ & 1978 & Ciencias Exactas y Naturales \\
\hline 3 & Doble Hélice. Impulsó: FJC-PCA & 1979 & Ciencias Exactas y Naturales \\
\hline 4 & Rafacles & 1980 & Filosofía y Letras \\
\hline 5 & Boletín de la Comisión de Antropología & 1980 & Filosofía y Letras \\
\hline 6 & Azul. Impulsó: FJC-PCA & 1980 & Arquitectura y urbanismo \\
\hline 7 & Base Cero. Impulsó decanato & 1980 & Ciencias Económicas \\
\hline 8 & Fuste & 1981 & Sin dato \\
\hline 9 & Fragüe & 1981 & Sin dato \\
\hline 10 & El Látigo & 1981 & Sin dato \\
\hline 11 & Enlaces. Impulsó: FJC-PCA & 1980 & Ciencias Exactas y Naturales \\
\hline 12 & Conciencia. Impulsó: FJC-PCA & 1981 & Psicología \\
\hline 13 & $\begin{array}{l}\text { Sopapa. Impulsó: Partido Socialista de los } \\
\text { Trabajadores }\end{array}$ & 1981 & Ciencias Económicas \\
\hline 14 & $\begin{array}{l}\text { Boletín Universitario. Partido Socialista } \\
\text { de los Trabajadores }\end{array}$ & 1981 & UBA \\
\hline 15 & $\begin{array}{l}\text { Hoja Estudiantil. Partido Socialista } \\
\text { de los Trabajadores }\end{array}$ & 1981 & UBA \\
\hline 16 & Unirse. Unión Nacional de Estudiantes & 1981 & Nacional \\
\hline 17 & $\begin{array}{l}\text { Espejos. Grupo independiente, luego Franja } \\
\text { Morada-Unión Cívica Radical }\end{array}$ & 1982 & Filosofía y Letras \\
\hline 18 & En Marcha. Impulsó: FJC-PCA & 1982 & Filosofía y Letras \\
\hline 19 & Encuentro. Órgano del Centro de Estudiantes & 1982 & Derecho \\
\hline 20 & Filo. Órgano del Centro de Estudiantes. & 1983 & Filosofía y Letras- \\
\hline
\end{tabular}

Elaboración propia a partir de consulta bibliográfica, acervos documentales públicos y archivos personales.

Arquitectura; también impulsaron publicaciones en la UBA la Juventud Universitaria del Partido Socialista de los Trabajadores, la Juventud Universitaria Peronista y la Unión de Juventudes por el Socialismo.

De todos modos, no todas las revistas surgieron por acción directa de militantes orgánicos de organizaciones políticas o estudiantiles. Identificamos el caso de Espejos, una revista editada por estudiantes de diversas carreras de la Facultad de Filosofía y Letras. Este grupo desarrolló un camino "inverso" a sus congéneres editoriales ya que iniciaron su actividad como un grupo "independiente" de alumnos y alumnas y en el segundo número de la 
revista se declararon como parte de la Franja Morada, agrupación universitaria ligada orgánicamente con la Unión Cívica Radical. También localizamos publicaciones realizadas desde Comisiones estudiantiles de base y, más tarde, desde los Centros de Estudiantes de las Facultades, donde participaban diversas fuerzas políticas ${ }^{20}$.

A este conjunto de publicaciones,

(...) impulsadas por militantes estudiantiles identificados con partidos políticos de izquierda con la participación activa de otros estudiantes sin actividad política orgánica, o bien aquellas impulsadas y desarrolladas en general por estudiantes sin militancia previa (...) no aprobadas o ilegalizadas por las autoridades de las facultades ${ }^{21}$.

las conceptualizamos como revistas estudiantiles "desde abajo". Las mismas se distinguen de aquellas "(...) desarrolladas bajo el estímulo, la regulación y la aprobación de las autoridades de las facultades, con participación de estudiantes (en su mayoría) sin experiencia de militancia política previa"22, que hemos denominado como revistas estudiantiles "desde arriba". Las primeras empezaron a surgir ya durante 1977, mientras que las segundas no aparecieron hasta 1980, en buena medida, como una respuesta a aquellas producidas autónomamente por el estudiantado en el marco de una actualización de la actitud de las autoridades hacia el alumnado con una relativa "apertura al diálogo" con la juventud universitaria ${ }^{23}$. Base Cero (1980-1982) en la Facultad de Ciencias Económicas, fue la expresión más acabada de esta propuesta.

La continuidad por parte de las revistas "desde abajo" fue más complicada. Estas se caracterizaron por su inestabilidad y fragilidad ya que se trataba de iniciativas fundamentalmente clandestinas en el marco de la prohibición de toda actividad gremial y política del estudiantado. Estos obstáculos, sumado a la movilidad estudiantil producto de la graduación o el cambio de intereses, dificultaba la regularidad editorial. A estos factores, debemos sumar otro fundamental como la aceleración de los tiempos políticos en

\footnotetext{
${ }^{20}$ Sobre la continuidad y la conformación de los Centros de Estudiantes y las comisiones estudiantiles de la UBA durante la última dictadura, véase Seia "De la revolución a la reforma": 140-167.

${ }^{21}$ Guadalupe Seia, "Las Revistas Estudiantiles en la Universidad de Buenos Aires durante la última dictadura (1976-1983)," en La condición juvenil en Latinoamérica: identidades, culturas y movimientos estudiantiles, ed. Ivonne Meza Huacuja y Sergio Moreno Juárez (México: UNAM, 2019): 218.

${ }^{22}$ Seia, "Las Revistas Estudiantiles": 218.

${ }^{23}$ Seia, "De la revolución a la reforma": 182-207.
} 
el marco del inicio de la transición democrática que, ya hacia mediados de 1982, concentró la atención y la actividad estudiantil en la renovación de autoridades de los Centros de Estudiantes así como también en la movilización contra la política universitaria de la dictadura ${ }^{24}$.

\section{Actitudes hacia la intervención y la dictadura ${ }^{25}$}

Ahora bien, que se tratara de revistas "desde abajo" clandestinas no suponía que las mismas se posicionaran con un discurso de oposición abierta al régimen dictatorial y/o a la intervención universitaria, como tampoco podemos simplificar la posición estudiantil en el marco de las revistas "desde arriba". Para avanzar sobre estos matices, la variable de la coyuntura política y universitaria es fundamental ya que los límites de lo posible y lo decible se fueron modificando a lo largo de la dictadura.

Las primeras revistas surgidas "desde abajo" tenían estrategias y objetivos diferentes. Arquitectura contra la Dictadura, como su título lo indica buscaba canalizar una estrategia de resistencia del peronismo revolucionario contra el régimen instaurado en 1976 a nivel universitario. Su revista inicialmente se proponía como un espacio de información contra la intervención universitaria, ya que denunciaba la complicidad de docentes y autoridades de la facultad en la puesta en marcha de un modelo educativo afín al proyecto militar. Esta revista no tuvo más que dos números en 1977, producto de la desarticulación de las células peronistas por la represión ${ }^{26}$.

En cambio, Interacción propuso una estrategia compartida con otras revistas impulsadas por el Partido Comunista como Aristócratas del Saber ${ }^{27}$ en el Colegio Nacional de Buenos Aires y Perspectiva Universitaria ${ }^{28}$. Juan Pa-

\footnotetext{
${ }^{24}$ Guadalupe Seia, "El movimiento estudiantil contra la política universitaria de la última dictadura en Argentina. El caso de la Universidad de Buenos Aires", Izquierdas, n. 49 (2020): 2213-2247.

${ }^{25}$ Para una comparación sobre la historiografía de las actitudes sociales Argentina bajo dictadura en España y, véase Lvovich, "Actitudes sociales y dictaduras".

${ }^{26}$ Es menester tener presente que entre 1976 y 1978 fueron asesinadas y/o secuestradas más de mil personas que estudiaban y/o trabajaban en las Facultades de la UBA. Se trata de más del 90\% del total de los casos contenidos en el Registro Único de Víctimas del Terrorismo de Estado.

${ }^{27}$ Véase Nadia Minghetti, "La prensa estudiantil como táctica de resistencia a la dictadura. El caso de la revista Aristócratas del Saber en el Colegio Nacional de Buenos Aires" (Tesis de Maestría, FLACSO, 2019).

${ }^{28}$ Véase Claudio Suasnábar, "Revista Perspectiva Universitaria. Voces disidentes en dicta-
} 
blo Paz, miembro de la Federación Juvenil Comunista y estudiante de Física, sostuvo que se habían dado la política de producir una revista para nuclear un grupo de estudiantes que no militaban orgánicamente alrededor de un proyecto que combinaba aspectos académicos, gremiales y algunas cuestiones políticas ${ }^{29}$. En ese marco, la revista no se presentada públicamente como iniciativa del comunismo en la universidad, sino como "(...) un importante medio de comunicación e información dentro de la facultad y para aquellos que se interesan por la ciencia en nuestro país" ${ }^{30}$. Interacción se definió como una revista de y para los estudiantes de Física de la UBA, con una fuerte impronta corporativa-gremial y de abordaje de problemáticas propias del desarrollo científico tanto a nivel nacional como internacional. El "camuflaje"31 de revista científica además de estudiantil le otorgó mayor margen de acción y circulación que sin embargo no se extendió en el tiempo ${ }^{32}$.

Ahora bien, ¿qué actitudes y posiciones desplegó Interacción ante la situación universitaria? ¿Y hacia la intervención dictatorial? En este punto, los matices respecto de Arquitectura contra la dictadura se multiplican en tanto, siguiendo la política del PC y la FJC, Interacción no planteó inicialmente cuestionamientos a la dictadura y sus representantes universitarios. En ese marco, en el segundo número (octubre de 1978), el Comité Editorial propuso al estudiantado una encuesta para conocerlo y dar voz a sus valoraciones sobre la carrera y la facultad. En la siguiente edición, se publicaron los resultados obtenidos de las respuestas de 132 estudiantes. Se destacó un grado alto de desilusión y/o insatisfacción del alumnado respecto de los planes de estudio, la escasez de docentes, la falta de materiales de laboratorio, las restricciones horarias para cursar, etc. Se trataba de los principales puntos de la agenda gremial retomada por las agrupaciones y los Centros de Estudiantes durante la etapa inicial de la dictadura ${ }^{33}$. Así, desde la revista y a partir de una encuesta, el comunismo posibilitaba que los estudiantes expresaran su descontento con la situación universitaria, aunque no se planteó un discurso crítico ni de denuncia a la intervención dictatorial de la UBA. Así, hasta fines de 1979, Inte-

\footnotetext{
dura," en Dictadura y Educación, ed. Carolina Kaufmann (Buenos Aires: Miño y Dávila, 2001).

${ }^{29}$ Entrevistas a Juan Pablo Paz, Buenos Aires, 2017. Realizada por G. Seia.

30 "Editorial", Interacción, n. 4, año II, octubre de 1979: 2.

${ }^{31}$ Tomamos la conceptualización de "camuflaje" de Iglesias, Escritores, dictadura y resistencia: 110.

${ }^{32}$ A finales 1979, Interacción fue prohibida por las autoridades de la facultad. Hasta ese momento, en cada número aparecían los nombres de los integrantes del Comité Editorial y de todos los colaboradores.

${ }^{33}$ Seia, "De la revolución a la reforma": 140-172.
} 
racción fue una revista estudiantil de la carrera de Física autorizada a circular en los claustros, que no mantenía una actitud opositora las autoridades interventoras. Sin embargo, para no recaer en la dicotomía consenso-resistencia, es factible sostener que se constituyó como un espacio de socialización, debate y organización alternativos a los autorizados por las autoridades universitarias y también, diferente de las agrupaciones y los Centros de Estudiantes. A la vez, la misma se conformó en un espacio de expresión y de canalización de inquietudes, descontento con la vida universitaria.

Marina Franco describe que en 1979 inició el "final del silencio" que intentó imponer el régimen del autodenominado "Proceso de Reorganización Nacional", a partir de la articulación de espacios de reunión y expresión de cierta crítica a aspectos del gobierno dictatorial acerca de la mala gestión económica y la postergada apertura política ${ }^{34}$. A nivel universitario, las agrupaciones estudiantiles describían un creciente interés por parte del estudiantado de reunirse a desarrollar actividades recreativas y también para empezar a discutir las problemáticas de la UBA. La sanción de la nueva ley universitaria en 1980 fomentó un clima de crítica hacia la política universitaria ${ }^{35}$.

En ese marco, entre 1979 y 1981, el mundo editorial estudiantil creció y se complejizó. Las publicaciones, los informes y los balances de las organizaciones de izquierda elaborados a principios de la década de 1980, destacaban el fenómeno de la proliferación de revistas culturales, de rock, juveniles en general, y estudiantiles en particular ${ }^{36}$. En esta sub-etapa, la producción editorial estudiantil se expandió considerablemente a pesar de las dificultades impuestas por la clandestinidad. Asimismo, las revistas estudiantiles "desde abajo" endurecieron sus posicionamientos críticos hacia la política universitaria de la dictadura. En concreto, la sanción de una nueva legislación universitaria funcionó como "bisagra" ${ }^{37}$. Dos estrategias fueron especialmente utilizadas para abordar dicha cuestión: el collage de recortes de la prensa nacional que referían al contenido del proyecto de ley y las críticas de diferentes actores al mismo, y las entrevistas con especialistas o personali-

${ }^{34}$ Marina Franco, El final del silencio, Dictadura, sociedad y derechos humanos en la transición (Argentina, 1979-1983) (Buenos Aires: FCE, 2018).

${ }^{35}$ Seia, "El movimiento estudiantil contra la política universitaria de la última dictadura en Argentina": 2233-2234.

${ }^{36}$ Véase el Cuadro 1 . A pesar de la existencia de más y nuevas revistas de este tipo hemos tenido dificultades para acceder a sus números. Hemos reconstruido su existencia a partir de otras fuentes documentales.

${ }^{37}$ Suasnábar, "Revista Perspectiva Universitaria", también identifica una reconfiguración de la estrategia de posicionamiento sobre la realidad universitaria alrededor del proyecto de ley universitaria. 
dades reconocidas en el ámbito de la cultura.

En 1981, las revistas estudiantiles "desde abajo" comenzaron publicar notas con críticas abiertas y directas a la política universitaria de la dictadura, en particular en contra del arancelamiento de los estudios de grado. Asimismo, difundían las actividades de protesta estudiantil y denunciaban la represión y la detención de estudiantes. También, planteaban que los espacios de agremiación estudiantil "naturales" eran los Centros de Estudiantes y las Federaciones. En ese sentido, la revista Sopapa de los estudiantes de Ciencias Económicas postulaba la urgencia de reconquistar la legalidad de los organismos estudiantiles históricos. Esta publicación no se situaba por fuera de la historia del movimiento estudiantil, sino como "(...) partícipe y bandera del proceso iniciado por el movimiento estudiantil en pro de la reconstitución de sus órganos de expresión y participación"38.

Este cambio debe enmarcarse en procesos políticos de varios niveles. En primer término, a nivel nacional, la presidencia de Roberto Viola habilitó un clima de relativa distensión política, relajación de la censura y de la represión. Esto favoreció la reactivación de la política partidaria y de la vida cultural que tomó forma con el surgimiento de la Multipartidaria y de una creciente movilización sindical opositora ${ }^{39}$. A nivel universitario el clima de "apertura" promovido por el discurso del nuevo ministro de educación, Carlos Burundarena, generaba expectativas entre ciertos sectores del movimiento estudiantil, así como también un marco de una relativa y creciente "libertad" para actuar en los claustros. En ese contexto, se consolidaron formas organizativas estudiantiles previas, surgieron otras nuevas y se desplegaron acciones gremiales de carácter opositor hacia la política universitaria ${ }^{40}$.

Estas posturas contrastaban de las revistas estudiantiles "desde arriba". En Base Cero observamos un discurso afín a la gestión interventora de la UBA y la búsqueda por constituirse como un espacio de participación para el alumnado alternativo y no complementario a las formas tradicionales del movimiento estudiantil, "válido, constructivo, noble, coherente" y reconocido por las autoridades de la facultad. Los aspectos específicos sobre la política universitaria de la dictadura también fueron atendidos por las revistas "desde arriba". Específicamente, Base Cero se ocupó de la implementación del arancel, retomando una preocupación generalizada del estudiantado. La

\footnotetext{
38 "Editorial", Sopapa, n. 1, 1981: 1.

${ }^{39}$ Franco, El final del silencio: 90.

${ }^{40}$ Sobre este momento re-fundacional del movimiento estudiantil porteño, véase Seia, "De la revolución a la reforma": 188-252.
} 
revista comunicó la información oficial (justificación, mecanismo de funcionamiento, montos, destino de lo recaudado, pedidos de excepción) y en contraste con la mayoría de los sectores estudiantiles, no se manifestó en contra de dicho arancelamiento, ni difundió convocatorias a movilizaciones.

Mientras que Base Cero puede ser analizado como un intento de las autoridades para contrarrestar las actividades independientes de los estudiantes, también debemos considerar la re-apropiación que el estudiantado hizo de este tipo de espacios. En concreto, “(...) había militantes de otras agrupaciones políticas que buscaban gente ahí, como también gente sin definición ideológica partidaria. Precisamente esto significó conocer más gente y comunicarse con mayor facilidad" ${ }^{\prime 1}$. Observamos, de este modo, cómo las iniciativas oficiales eran aprovechados por la militancia estudiantil para conocer estudiantes e intercambiar ideas respecto de la situación de la facultad y la universidad.

El desarrollo de la Guerra por las Islas Malvinas en el Atlántico Sur durante el primer semestre de 1982 abrió una brecha a nivel de la vida política nacional y también en la universidad. Esa oportunidad fue aprovechada por las agrupaciones estudiantiles que se dispusieron a desarrollar actividades públicas en las facultades, iniciando un proceso de legalización de hecho del movimiento estudiantil ${ }^{42}$. En ese marco, como se observa en el Cuadro 1, surgieron nuevas revistas estudiantiles "desde abajo". Incluso, durante 1982 se constituyó la Comisión de Revistas Estudiantiles de la UBA (CREUBA) donde participaban 12 publicaciones también nucleadas en una instancia nacional.

En esta nueva etapa, las publicaciones "desde abajo" plantearon cuestionamientos a la política universitaria y a la dictadura en general de manera abierta, en algunos casos, tomando declarada posición política. Sostenían que los estudiantes debían ser parte de la discusión sobre el tipo de país que debía ser la Argentina democrática y el modelo de universidad que lo iba a acompañar. De este modo, expresaban la demanda del estudiantado por espacios de participación, revalorizando los principios de la Reforma Universitaria de $1918^{43}$. En cambio, la línea editorial de la revista "desde arriba" Base Cero planteaba abiertamente críticas al movimiento estudiantil. Según la publicación, la universidad se encontraba en una encrucijada entre "la radicalización política" y "la moderación, la amplitud y la libertad de pensamiento". En ese

${ }^{41}$ Ariel Alegre en Laura Polak y Juan Gorbier, El movimiento estudiantil argentino (Franja Morada 1976-1986) (Buenos Aires: CEAL, 1994): 64.

${ }^{42}$ Seia, "De la revolución a la reforma": 253-274.

${ }^{43}$ Guadalupe Seia, "El reformismo universitario entre la dictadura y la democracia. Un análisis del movimiento estudiantil de la UBA entre 1976 y 1983," Cuadernos de Historia, n. 21 (2018): 166-191. 
sentido, cuestionaba a los militantes de las agrupaciones que asistían a las facultades para "hacer política". Así, mientras las revistas "desde abajo" apostaban, apoyaban o incluso eran producto de la creciente organización estudiantil en las Comisiones y Centros, Base Cero cuestionaba este modelo de participación porque implicaba la politización de los espacios estudiantiles que, como sostenía el discurso dictatorial, era el origen de la radicalización política y la amenaza al orden social todo. Sin embargo, en plena crisis terminal de la dictadura, en Base Cero comenzaron a expresarse críticas a la política universitaria y a la conducción de la UBA, particularmente a la ley universitaria, los concursos docentes, la falta de autonomía universitaria para la designación de las autoridades. Estos planteos eran novedosos para una publicación que contaba con el respaldo de las autoridades. Observamos una operación de distanciamiento de aquellos rasgos de la política universitaria más cuestionados, junto a la incorporación de algunos de sus lineamientos básicos respecto del modelo de universidad propuesto y al lugar del estudiante.

\section{Las revistas estudiantiles en España durante el franquismo (1939-1975) ${ }^{44}$}

La prensa de los estudiantes en España no fue una novedad de la etapa franquista, José Hernández Díaz localiza su origen en las universidades europeas en el último tercio del siglo XIX y la identifica como una de las manifestaciones de la vitalidad asociativa de los estudiantes ${ }^{45}$. Según el autor, las publicaciones tienen para el colectivo estudiantil diversas funciones, entre ellas: el afianzamiento de la vida asociativa, la comunicación e información y formación, el disfrute, la denuncia, la búsqueda de influir sobre un sector más amplio del alumnado o incluso sobre las políticas universitarias. Así, la prensa estudiantil universitaria en España ha ofrecido “(...) un perfil polimórfico, a veces

${ }^{44}$ Véase Cuadros 2 y 3 . Estos listados no son definitivos, aspiramos a que resulten un aporte significativo y un estímulo para avanzar colectivamente en su ampliación.

${ }^{45}$ José Hernández Díaz, "La prensa de los estudiantes en España. Justificación pedagógica y tipología”, en La prensa de los escolares y estudiantes: Su contribución al patrimonio histórico educativo, ed. José Hernández Díaz (Salamanca: Ed. Universidad de Salamanca, 2015): $377-$ 394. Por ejemplo, Luciana Carreño describe el rol pionero de la revista El Estudiante, publicada entre 1925 y 1926 en Salamanca y Madrid, en la oposición a la dictadura primoriverista en España, así como también en la construcción de lazos de solidaridad con las juventudes universitarias latinoamericanas ligadas al movimiento de la Reforma Universitaria ("La Federación Universitaria Hispanoamericana en Madrid," CIAN-Revista de Historia de las Universidades, n. 16 (2013): 51-80). 
rebelde y crítico, en ocasiones conformista (...)"46. En función de estos señalamientos, Hernández Díaz propone una clasificación de siete tipos de prensa estudiantil: 1) de uniones escolares, asociaciones y sindicatos de alumnos; 2) de orientación pre-profesional; 3) “con apellido político"47; 4) de los estudiantes católicos; 5) de los colegios mayores y residencias universitarias; 6) de los centros eclesiásticos; 7) de ocio, tiempo libre y literatura. Estas publicaciones se han caracterizado por ser modestas, de tiradas pequeñas, elaboradas con medios precarios, logrando una periodicidad irregular y una vida corta ${ }^{48}$.

Específicamente durante los años de la dictadura franquista, como muestran los Cuadros 2 y 3 , las revistas estudiantiles se constituyeron como un fenómeno, aunque no novedoso, si relevante, extenso y heterogéneo que se reconfiguró a lo largo de la etapa y que no puede ser aislado del desarrollo del movimiento estudiantil español. A continuación, presentamos una descripción general de las revistas estudiantiles durante el franquismo, particularmente la prensa de las asociaciones y sindicatos estudiantiles, las identificadas por su "apellido político" y la de ocio y tiempo libre.

A diferencia del notable trabajo de caracterización y catalogación de la prensa estudiantil y juvenil durante la guerra civil ${ }^{49}$, no contamos con una sistematización similar para las casi cuatro décadas de franquismo, a excepción del extenso estudio de Ruiz Carnicer sobre la prensa universitaria del Sindicato Español Universitario (SEU) $)^{50}$. Encontramos, por otra parte, estudios de caso sobre algunas publicaciones clandestinas y seuístas de diferentes ciudades de España durante la etapa que nos interesa ${ }^{51}$. En función de estos antecedentes y de los interrogantes que guiaron nuestro estudio

${ }^{46}$ Hernández Díaz, J. “La prensa de los estudiantes”: 378.

${ }^{47}$ Aquellas donde se recogían los temas de actualidad que interesaban a los jóvenes del momento y también de asuntos educativos y universitarios desde una lectura partidista (Hernández Díaz, "La prensa de los estudiantes": 386).

${ }^{48}$ Hernández Díaz, J. “La prensa de los estudiantes”: 382.

${ }^{49}$ Julio Aróstegui, Historia y memoria de la Guerra Civil: encuentro en Castilla y León: Salamanca, 24-27 de Septiembre de 1986. Prensa juvenil y estudiantil durante la guerra civil (19361939): caracterización y catalogación (Valladolid: Junta de Castilla y León, 1988): 229-341.

${ }^{50}$ Miguel Ángel Ruiz Carnicer, "La voz de la juventud. Prensa universitaria del SEU en el franquismo," Bulletin Hispanique, tomo 98, n. 1 (1996): 175-199.

${ }^{51}$ Raúl Malmierca, "Prensa estudiantil clandestina en la Universidad de Salamanca. La publicación de Acción durante el tardofranquismo en Salamanca (1969-1976)", en La prensa de los escolares y estudiantes: 177-178; Sara González Gómez, "Prensa universitaria salamantina durante la segunda mitad del franquismo", en La prensa de los escolares y estudiantes: 439450; Juan Rubio Mayoral y Guadalupe Tringueros Gordillo, "Estudio y acción. Información, propaganda política e ideología en la prensa universitaria hispana (1939-1968)", en La prensa de los escolares y estudiantes: 539-553. 
sobre el caso argentino, proponemos una clasificación complementaria a la de Hernández Díaz, para desde allí proponer líneas de interpretación desde una perspectiva comparada ${ }^{52}$. En adelante concentramos nuestra reflexión sobre aquellas revistas estudiantiles durante el franquismo catalogables en dos grandes grupos: por un lado, la prensa legal del SEU, y por otro, a las publicaciones estudiantiles "desde abajo". En adelante, presentamos sintéticamente sus rasgos principales, apostando a identificar también los matices y las complejidades propios de las experiencias de sociabilidad y politización estudiantil durante el siglo XX.

Las revistas del Sindicato Español Universitario: legales iy oficialistas? (19391965)

Hernández Díaz (2015) ubica a las publicaciones editadas por el SEU entre las revistas elaboradas por el alumnado que habitaba los Colegios Mayores y las Residencias Universitarias. Consideramos que esta catalogación merece ser precisada en tanto esta prensa a la vez que era publicada por asociaciones estudiantiles, tenía una identificación política abierta con la Falange y el bando franquista, así como también la agremiación al mismo era obligatoria para el conjunto del alumnado universitario de España. En ese sentido, encontramos estudios que resaltan la labor de propaganda y adoctrinamiento desarrollado desde las publicaciones seuístas (Haz, El Compostelano, Amanecer, Juventud) durante la guerra civil y también bajo el gobierno dictatorial de Francisco Franco, sobre todo durante los primeros años del régimen ${ }^{53}$.

Esta identificación ideológica y desarrollo doctrinario presente en las revistas del SEU se complementaba con la publicidad de las actividades y los logros gremiales del sindicato. Al respecto, Ruiz Carnicer sostiene que una vez finalizada la guerra, desde el SEU se buscó impulsar una publicación más "flexible" y cercana al estudiantado, así Haz adquirió un estilo más popular con un contenido político e informativo sobre la universidad. En las publicaciones del distrito universitario de Sevilla (Universidad y Actualidad Universitaria)

${ }^{52}$ No se trata de una presentación acabada de la totalidad de publicaciones que circularon en esos años, ni siquiera de las que actualmente es posible consultar en diferentes repositorios documentales. Con nuestra descripción pretendemos proponer una línea de interpretación que pueda ser problematizada a partir del trabajo con revistas estudiantiles aquí no incluidas.

${ }^{53}$ Isaura Varela González y Miguel Ángel Ruiz Carnicer, "Prensa juvenil y estudiantil en el bando franquista durante la guerra civil (1936-1939)", en Historia y memoria de la Guerra Civil: 231-238; Ruiz Carnicer, "La voz de la juventud”: 177. 
Cuadro 2. Publicaciones del Sindicato Español Universitario (1939-1965)

\begin{tabular}{|c|l|c|c|}
\hline \multicolumn{1}{|c|}{ Título y editor } & Fecha & Ciudad \\
\hline 1 & Haz & $1935-1955$ & Madrid \\
\hline 2 & Alerta & 1942 & Barcelona \\
\hline 3 & Cátedra & $1942-1945$ & Salamanca/Sevilla \\
\hline 4 & Guía & $1956-1965$ & Madrid \\
\hline 5 & Juventud & $1942-1959$ & Madrid \\
\hline 6 & La Hora & $1945-1950$ & Madrid \\
\hline 7 & Alférez & $1947-1949$ & Madrid \\
\hline 8 & Alcalá & $1952-1955$ & Madrid \\
\hline 9 & Laye & $1950-1954$ & Barcelona \\
\hline 10 & Revista & $1952-1956$ & Barcelona \\
\hline 11 & El Gallo & $1953-1968$ & Salamanca \\
\hline 12 & Cinema Universitario & $1955-1963$ & Salamanca \\
\hline 13 & Universidad, portavoz de los estudiantes de Sevilla & $1952-1956$ & Sevilla \\
\hline 14 & La actualidad, revista informativa del SEU & 1955 & Sevilla \\
\hline 15 & Noticia & $1955-1958$ & Madrid \\
\hline 16 & Acento Cultural & $1958-1961$ & Madrid \\
\hline 17 & Aljibe & 1954 & Sevilla \\
\hline 18 & Libélula & $1954-1955$ & Sevilla \\
\hline & & & \\
\hline
\end{tabular}

Elaboración propia a partir de consulta bibliográfica y acervos documentales públicos.

encontramos secciones y hasta separatas especiales (Anaquel) para la difusión de un conjunto de actividades religiosas, culturales, deportivas, así como también los logros en materia de vivienda para los estudiantes gestionados desde el sindicato ${ }^{54}$. Dicho registro publicitario del propio SEU continuó presente en las publicaciones a lo largo de los años, incluso cuando en estas comenzó a hacerse visible cierta inconformidad con el régimen y la realidad española por parte de los miembros del sindicato (por ejemplo en La Hora, segunda época). Al respecto, existe un fuerte consenso historiográfico acerca de que

(...) el SEU constituyó en los años cincuenta el frente más activo y, sobre todo, tolerado de cultura disidente y crítica con los fundamentos ideológicos del régimen, aunque sus procedimientos fuesen indirectos y crípticos o funcionase sólo a través de la circulación de libros e ideas inaccesibles fuera de la protección falangista ${ }^{55}$.

\footnotetext{
${ }^{54}$ Rubio Mayoral y Tringueros Gordillo, "Estudio y acción”.

${ }^{55}$ Jordi García, Estado y cultura: el despertar de una conciencia crítica bajo el franquismo, 1940-1962 (Barcelona: Anagrama, 2006): 74.
} 
Ya durante la década de 1950, ciertas publicaciones del SEU expresaron y canalizaron los debates acerca de la necesidad e importancia de una apertura cultural, incluyendo textos, temas, crónicas sobre cuestiones que se salían de límites de lo aceptado por la dictadura. Revistas como Laye, Alcalá, El Gallo ${ }^{56}$, y Universidad se conformaron como híbridos de ortodoxia política y posiciones inconformistas y aperturistas y lograron una importancia cultural notable, que no necesariamente se condecía con su difusión entre la mayoría del alumnado.

En ese marco, se desarrollaron revistas especializadas en temas culturales como Acento, Cinema Universitario, Aljibe y Libélula que abordaban cuestiones de cine, literatura, teatro, y que tuvieron un papel importante en el proceso de apertura y cuestionamiento al status quo. Consideramos entonces que las publicaciones de este tipo, editadas desde el SEU, constituyen un tipo peculiar de híbrido en donde se funden las tipologías propuestas por Hernández Díaz, arte, ocio y tiempo libre, sumado a la pertenencia orgánica al SEU. Dicha pertenencia fue la que brindó ciertos niveles de autonomía relativa para incorporar debates, lecturas, cuestionamientos "desde adentro" al régimen. Ya durante la década de 1960, ese proceso de distanciamiento se cristalizó en la ruptura de ciertos sectores de las juventudes falangistas con el sindicato y la dictadura, incorporándose a organizaciones de la izquierda ${ }^{57}$.

Nos interesa, ahora, poner en juego críticamente la categoría de revistas estudiantiles "desde arriba" propuesta para el caso argentino, incorporando la variedad de elementos y matices que caracterizaron la experiencia editorial legal del SEU. Esta era una organización pre-existente a la dictadura que se integró al régimen y constituyó la única asociación política y gremial estudiantil autorizada a funcionar con la oportunidad y la necesidad de difundir su ideario político a través de revistas. Sus publicaciones, que también habían surgido antes del inicio de la dictadura, fueron reconfigurándose para responder a la coyuntura política y universitaria, generando nuevos proyectos, actualizando otros y sumando expresiones locales por distritos. Fue, en parte, su condición de prensa legal y "oficialista", aceptada pero no impulsada ni gestada "desde arriba" (a diferencia de las revistas estudiantiles afines a la intervención dictatorial en Argentina) la que les brindó una autonomía relativa para incorporar lecturas, debates y también críticas evitando la cen-

\footnotetext{
${ }^{56}$ González Gómez, "Prensa universitaria salamantina".

${ }^{57}$ Miguel Ángel Ruiz Carnicer, "Jóvenes, intelectuales y falangistas: apuntes sobre el proceso de ruptura con la dictadura en los años sesenta," Cercles, N. 16 (2013): 103-122.
} 
sura. Durante las décadas de 1950 y 1960, a través de las revistas se expresaron y agudizaron las contradicciones existentes entre un SEU leal al Estado franquista y un sindicato estudiantil que se hacía eco del despertar social y político de la juventud española, y que finalmente caería en el olvido ante el avance y la consolidación de la organización estudiantil "desde abajo", democrática y autónoma. En contraste con las revistas "desde arriba” argentinas, la prensa del SEU no fue una respuesta tardía a la re-organización estudiantil, sino una apuesta temprana planificada y sostenida desde el estado que apostaban a un modelo de organización estudiantil centralizado, tutelado y antidemocrático, aunque en su interior pudieron gestarse oposiciones y resistencias para finalmente romper con ella. Al considerar la heterogeneidad de medios y publicaciones del SEU, así como su reconfiguración a lo largo de estas décadas, encontramos los límites y los matices necesarios para el uso de la categorización "desde arriba" en la prensa seuísta. A la vez, el ejercicio permite identificar las particularidades de los fenómenos de la prensa estudiantil legal bajo las dictaduras en España y Argentina.

\section{Las revistas estudiantiles "desde abajo" (1939-1975) ${ }^{58}$}

La prensa estudiantil del bando anti-franquista fue aún más diversa e irregular que la del SEU. Esta fue ilegalizada en el marco de la represión y prohibición de las asociaciones y agrupaciones estudiantiles republicanas y de izquierda. Hernández Díaz sostiene que las publicaciones de las organizaciones gremiales estudiantiles y también aquellas "con apellido político" tuvieron un "espectacular resurgir" durante la década de 1970 con la consolidación del movimiento estudiantil opositor a la dictadura ${ }^{59}$. A continuación, proponemos una periodización más amplia que la del autor para dar cuenta del proceso de recuperación temprano de la tradición editorial por las asociaciones estudiantiles y las agrupaciones políticas universitarias bajo el franquismo.

${ }^{58}$ Insistimos en que se trata de una clasificación complementaria a otras como la que propone Hernández Díaz, que no pretende invisibilizar la variedad y el volumen de la prensa estudiantil española. El listado del Cuadro 3 ilustra parcialmente dicha heterogeneidad.

${ }^{59}$ Hernández Díaz, "La prensa de los estudiantes": 384. Sobre la prensa estudiantil antifranquista durante la guerra civil, véase Fernanda Mancebo y Josep Vivó, "Análisis temático de la prensa de las asociaciones estudiantiles (publicaciones de la UFEH-FUE y la FNEC)", en Historia y memoria de la Guerra Civil: 259-278. 
Cuadro 3. Publicaciones estudiantiles "desde abajo" en España (1945-1975)

\begin{tabular}{|c|c|c|c|}
\hline $\mathbf{N}^{\circ}$ & Título y editor & Fecha & Ciudad \\
\hline 1 & $\begin{array}{l}\text { FUE. Órgano de la Federación de Madrid de la Unión } \\
\text { Federal de Estudiantes Hispanos }\end{array}$ & 1945 & Madrid \\
\hline 2 & $\begin{array}{l}\text { Frente Universitario. La prensa estudiantil de la } \\
\text { clandestinidad. Comité de Coordinación UFEN-FNEC }\end{array}$ & 1946 & Madrid \\
\hline 3 & Universitat. Revista universitaria del PSUC & $1958-1977$ & Barcelona \\
\hline 4 & $\begin{array}{l}\text { Cuadernos del Aula de Cultura: Los problemas } \\
\text { actuales vistos por los universitarios. }\end{array}$ & $1961-1962$ & Sevilla \\
\hline 5 & Peñafort & $1962-1967$ & Sevilla \\
\hline 6 & Hospital & $1962-63$ & Sevilla \\
\hline 7 & La avispa & $1962-63$ & Sevilla \\
\hline 8 & $\begin{array}{l}\text { Boletín informativo estudiantes españoles. Delegación } \\
\text { exterior. }\end{array}$ & 1963 & - \\
\hline 9 & $\begin{array}{l}\text { Boletín conjunto de las escuelas miembro de } \\
\text { la Federación de Estudiantes de Arquitectura e } \\
\text { Ingeniería y de las Facultades de Ciencias, Derecho, } \\
\text { Económicas, Filosofía y Medicina en Madrid }\end{array}$ & 1964 & Madrid \\
\hline 10 & $\begin{array}{l}\text { Boletín informativo CCPPEE. Dpto. información y } \\
\text { prensa }\end{array}$ & 1965 & Madrid \\
\hline 11 & Vanguardia. Órgano universitario del PCE de España & $1965-1977$ & Madrid \\
\hline 12 & Crítica. Revista dels estudiants del PSUC & 1964 & Barcelona \\
\hline 13 & Politécnico. Órgano del PCE & 1966 & Madrid \\
\hline 14 & $\begin{array}{l}\text { Boletín Informativo de la Facultad de de Ciencias de } \\
\text { Madrid }\end{array}$ & 1966 & Madrid \\
\hline 15 & $\begin{array}{l}\text { Boletín Informativo del Sindicato Democrático de la } \\
\text { Facultad de Ciencias Políticas y Económicas. }\end{array}$ & 1967 & Madrid \\
\hline 16 & $\begin{array}{l}\text { Boletín Informativo de la Facultad de Filosofía y } \\
\text { Letras. Edita delegación alumnos. }\end{array}$ & 1967 & Madrid \\
\hline 17 & $\begin{array}{l}\text { Boletín informativo Asociación Alumnos de la } \\
\text { Escuela de Ingeniería Técnica Industrial }\end{array}$ & 1967 & Madrid \\
\hline 18 & $\begin{array}{l}\text { Corriente. Periódico de los simpatizantes de la LCR } \\
\text { de Ciencias Políticas. }\end{array}$ & 1967 & Madrid \\
\hline 19 & Unitá. Órgano del Comité de estudiantes del PCE & 1968 & Valencia \\
\hline 20 & $\begin{array}{l}\text { Crítica. Órgano del Comité Universitario del PCE de } \\
\text { Zaragoza }\end{array}$ & 1968 & Zaragoza \\
\hline 21 & Universidad del Pueblo. Órgano teórico de la FUDE. & 1968 & Salamanca \\
\hline 22 & $\begin{array}{l}\text { Comuna FUDE. Órgano de la Agrupación Estudiantil } \\
\text { Revolucionaria fusionada con Revolución Socialista } \\
\text { de Barcelona }\end{array}$ & 1968 & Madrid \\
\hline 23 & $\begin{array}{l}\text { Realidad. Agrupación sindical de la facultad de } \\
\text { Ciencias }\end{array}$ & 1968 & Valencia \\
\hline 24 & $\begin{array}{l}\text { Diàleg, revista decana de la Universidad de Valencia. } \\
\text { Sindicato de estudiantes de la Facultad de Derecho }\end{array}$ & 1968 & Valencia \\
\hline
\end{tabular}




\begin{tabular}{|c|c|c|c|}
\hline $\mathbf{N}^{\circ}$ & Título y editor & Fecha & Ciudad \\
\hline 25 & Modulo 68. Revista de la Escuela de Arquitectura & 1968 & Valencia \\
\hline 26 & $\begin{array}{l}\text { Sou. Revista de la Facultad de Ciencias políticas, } \\
\text { económicas y comerciales. }\end{array}$ & 1968 & Valencia \\
\hline 27 & Terra Nostra. Revista de la Escuela de Agronomía & 1968 & Valencia \\
\hline 28 & $\begin{array}{l}\text { Acción. Órgano del Comité Universitario del PCE en } \\
\text { Salamanca }\end{array}$ & $1969-1976$ & Salamanca \\
\hline 29 & $\begin{array}{l}\text { Lucha. Órgano del Comité del PCE de la universidad } \\
\text { de Oviedo }\end{array}$ & 1969 & Oviedo \\
\hline 30 & $\begin{array}{l}\text { Lucha Estudiantil. Portavoz de las comisiones } \\
\text { estudiantiles de Murcia }\end{array}$ & 1969 & Murcia \\
\hline 31 & $\begin{array}{l}\text { Acción estudiantil. Órgano universitario del Frente } \\
\text { de Liberación Popular }\end{array}$ & 1969 & \\
\hline 32 & $\begin{array}{l}\text { Prensa Libre. Boletín Informativo del Sindicato } \\
\text { Democrático de Estudiantes }\end{array}$ & 1969 & \\
\hline 33 & $\begin{array}{l}\text { Democracia popular. Órgano de la Federación } \\
\text { Universitaria Democrática Española (FUDE) }\end{array}$ & $1969-1972$ & \\
\hline 34 & $\begin{array}{l}\text { Tribuna. Órgano de la agrupación universitaria del } \\
\text { PCE de Valladolid }\end{array}$ & 1970 & Valladolid \\
\hline 35 & $\begin{array}{l}\text { Folga. Órgano de la organización estudiantil del PCE } \\
\text { de Galicia }\end{array}$ & 1970 & Galicia \\
\hline 36 & $\begin{array}{l}\text { Universidad Popular. Tribuna libre de los estudiantes } \\
\text { en la Universidad Autónoma de Madrid }\end{array}$ & 1970 & Madrid \\
\hline 37 & Progreso. & 1970 & Murcia \\
\hline 38 & En pie. Órgano universitario de la Laguna del PCE. & 1972 & Tenerife \\
\hline 39 & Galileo. Revista de cultura y política de la LCE & 1972 & Madrid \\
\hline 40 & $\begin{array}{l}\text { Estudiante Comunista. Portavoz de la organización } \\
\text { universitaria del PCE de la Facultad de Ciencias } \\
\text { Económicas }\end{array}$ & 1972 & Madrid \\
\hline 41 & $\begin{array}{l}\text { Lucha Estudiantil. Comisión del distrito universitario } \\
\text { de Madrid }\end{array}$ & 1972 & Madrid \\
\hline 42 & $\begin{array}{l}\text { Medicina socialista, Portavoz de la organización } \\
\text { universitaria del PCE de la Facultad de Medicina. }\end{array}$ & $1972-1973$ & Madrid \\
\hline 43 & $\begin{array}{l}\text { Nuestra lucha, órgano del comité de la Universidad } \\
\text { Autónoma de Madrid del PCE }\end{array}$ & 1973 & Madrid \\
\hline 44 & $\begin{array}{l}\text { Revista informativa de los alumnos. Facultad de } \\
\text { Derecho }\end{array}$ & $1973-1975$ & Sevilla \\
\hline 40 & $\begin{array}{l}\text { Boletín Universitario. Portavoz de la organización } \\
\text { universitaria del PCE en La Laguna }\end{array}$ & 1974 & Tenerife \\
\hline 41 & $\begin{array}{l}\text { Unidad, Órgano del comité universitario del PCE de } \\
\text { Granada }\end{array}$ & 1974 & Granada \\
\hline 42 & Crítica. Órgano universitario del PCE & 1974-1977 & Madrid \\
\hline 43 & $\begin{array}{l}\text { Universidad. Órgano del Comité Universitario de } \\
\text { Sevilla del PCE }\end{array}$ & 1973 & Sevilla \\
\hline
\end{tabular}




\begin{tabular}{|c|c|c|c|}
\hline $\mathbf{N}^{\circ}$ & Título y editor & Fecha & Ciudad \\
\hline 44 & $\begin{array}{l}\text { Boletín Informativo. Agencia Democrática de } \\
\text { información de la Universidad de Madrid }\end{array}$ & 1973 & Madrid \\
\hline 45 & $\begin{array}{l}\text { Vector libre. Revista de los estudiantes de la Facultad } \\
\text { de Ciencias. }\end{array}$ & 1974 & Sevilla \\
\hline 46 & El ladrillo. Revista de los estudiantes de Medicina. & 1974 & Sevilla \\
\hline 47 & $\begin{array}{l}\text { ETSA. Escuela Técnica Superior de Arquitectura de } \\
\text { Sevilla }\end{array}$ & 1974 & Sevilla \\
\hline 48 & Publicación Universitaria vasca del Frente Cultural & 1974 & Bilbao \\
\hline 49 & $\begin{array}{l}\text { Universidad Roja. Portavoz de militantes y } \\
\text { simpatizantes en la universidad de LCR-ETA VI }\end{array}$ & 1975 & Bilbao \\
\hline
\end{tabular}

Elaboración propia a partir de consulta bibliográfica y acervos documentales públicos (Archivo Histórico del PCE, Madrid y Archivo Histórico de las Comisiones Obreras, Sevilla).

En función de la reconstrucción que presentamos aquí, ubicamos un proceso progresivo de surgimiento de publicaciones estudiantiles clandestinas ${ }^{60} \mathrm{y}$ "desde abajo" en diferentes universidades de España desde la segunda mitad de la década de 1940. Los militantes universitarios procuraron reconstruir la Unión Federal de Estudiantes Hispanos (UFEH) y la Federación Universitaria Escolar (FUE) en algunos distritos ${ }^{61}$. Dichos intentos llevaron a la edición de FUE, el órgano de la Federación de Madrid de la UFEH en 1945 y de Frente Universitario, autodenominada como "la prensa estudiantil de la clandestinidad" en 1946. Sin embargo, producto de las pésimas condiciones de producción, éstas fueron experiencias efímeras.

Las investigaciones sobre el movimiento estudiantil ubican a partir del último tercio de la década de 1950 el crecimiento de los desarrollos editoriales estudiantiles, fundamentalmente los estimulados por la militancia universitaria del PCE que luego de los sucesos de 1956 cobró impulso y apostó, como en el caso argentino, al desarrollo de medios de información clandestinos. Estas publicaciones reunían

(...) lecturas sobre elementos internos de cada universidad, denuncias sobre abusos de rectores o profesores, artículos de opinión sobre la universidad en el proyecto

60 "Podemos englobar dentro de la prensa estudiantil clandestina, a aquellos órganos de expresión producidos por estudiantes de cualquier etapa del sistema educativo formal, secretamente por temor a la ley o para eludirla." en palabras de Malmierca, "Prensa estudiantil clandestina": 177-178.

${ }^{61}$ Sobre la FUE, véase Sergio Rodríguez Tejada, Zonas de libertad. Dictadura franquista y movimiento estudiantil en la Universidad de Valencia. Vol. I (1939-1965) (Valencia: Publicaciones de la Universidad, 2009): 137-166. 
de una España en libertad y democrática y contra la dictadura franquista, y desde categorías revolucionarias, pero sobre todo las ideas claves y centrales del proyecto político del PCE $(\ldots)^{62}$.

En el Cuadro 3 se puede observar la extensión de la iniciativa editorial de la izquierda en las diferentes universidades españolas. A diferencia de la iniciativa argentina, en general, la prensa estudiantil española no solo recurrió a una estrategia de "camuflaje", sino que también incluyó una variedad de órganos de comunicación de agrupaciones y asociaciones estudiantiles ${ }^{63}$. Entre las publicaciones tempranas y con mayor continuidad se destacaron Universitat (1958) en Barcelona y Vanguardia (1965) en Madrid. A partir de la segunda mitad de la década de 1960, el campo editorial estudiantil creció exponencialmente y se consolidó. Este fenómeno no puede entenderse desconectado de las experiencias previas ni del proceso de socialización política y cultural del estudiantado universitario de esos años:

La universidad española desde los años sesenta era, en efecto, un hervidero político, sólo comparable, y con sus diferencias circunstanciales, al que se notaba en el mundo obrero, el otro gran frente de lucha contra la dictadura. Cotidianamente no debió existir en España un lugar donde más se hablaba de política, donde más actividades de orientación política, manifiesta o encubierta, se realizaban. Entre éstas últimas destacaron una parte de las actividades culturales realizadas a través de las aulas de cultura, verdaderos cuarteles generales del movimiento estudiantil; las revistas, tradicionales y murales; recitales poéticos, conciertos, conferencias, etc. Y por supuesto, las acciones políticas en sentido estricto derivadas de la acción de las organizaciones clandestinas y sus militantes que se multiplicaron de manera prodigiosa ${ }^{64}$.

La acción estudiantil antifranquista fue creciendo en intensidad y extensión, cristalizando también en asociaciones estudiantiles democráticas y en el crecimiento de otras tendencias políticas de izquierda radical, que como se observa en el Cuadro 3 también editaron sus publicaciones ${ }^{65}$. Asimismo, encontramos las revistas ligadas a los espacios de producción y debate cultural como Cuadernos del Aula de Cultura y a las problemáticas de cada Peñafort, Hospital, La Avispa en Sevilla o los Boletines Informativos por

\footnotetext{
${ }^{62}$ Hernández Díaz, "La prensa de los estudiantes”: 388.

${ }^{63}$ Como hemos señalado, ninguna de las publicaciones estudiantiles de la UBA se declaró como órgano comunicativo de una fuerza política.

${ }^{64}$ Alberto Carrillo-Linares, "Universidades y transiciones políticas: el caso español en los años 60-70," Espacio, Tiempo y Educación, n. 2, v. 2 (2015): 61.

${ }^{65}$ Sobre el desarrollo de estas organizaciones, véase Carrillo-Linares, Subversivos y malditos: 31-81.
} 
facultad de prácticamente todas las universidades de España con un discurso crítico y en algunos casos satírico hacia la vida en las universidades españolas del franquismo ${ }^{66}$.

La eclosión editorial en las universidades españolas se dio como producto del y a la vez estimuló el ciclo de movilización estudiantil de 1968 que tuvo su capítulo en numerosas ciudades del país ibérico. En el Cuadro 3 encontramos el registro de más quince publicaciones sólo para las ciudades de Valencia, Zaragoza, Madrid, Salamanca, Oviedo y Murcia, entre ellas: órganos de comunicación de los comités universitarios del PCE y de otras organizaciones de izquierda como la FUDE, de los sindicatos democráticos y las agrupaciones sindicales de las facultades. Asimismo, entre 1969 y 1972, localizamos las publicaciones de otras expresiones de organización estudiantil como los Comités de curso que se presentaban como una alternativa revolucionaria a los sindicatos democráticos ${ }^{67}$. El estado de situación del campo de la prensa estudiantil expresaba la situación de efervescencia política y social de los universitarios, así como también los debates tácticos y estratégicos al interior del movimiento estudiantil y de la izquierda española y europea.

Al iniciarse la década de 1970, el PCE continuó inaugurando órganos de comunicación de sus agrupaciones en ciudades como Valladolid, Galicia, Granada, Sevilla y Tenerife e impulsó también revistas por facultad en las universidades donde la organización ya se encontraba consolidada. Asimismo, comenzaron a surgir publicaciones en las recientemente creadas universidades autónomas. Esta era una novedad para las publicaciones estudiantiles "desde abajo" con "apellido político", aunque se contaba con las experiencias previas de los boletines informativos por facultad.

En Sevilla, circularon nuevas revistas impulsadas por las Aulas de Cultura de las facultades de Medicina, Ciencias y Arquitectura. En los números de estas revistas que pudimos consultar encontramos interesantes similitudes en la estructura, las temáticas abordadas, el registro, el uso de los recortes de la prensa nacional, entre otras, respecto de las experiencias de las revistas "desde abajo" por carrera de la UBA durante la dictadura. Incluso, como en la UBA, las revistas estudiantiles hispalenses compartieron un número especial sobre la reforma educativa y la sanción de la nueva ley de uni-

\footnotetext{
${ }^{66}$ Rubio Mayoral y Tringueros Gordillo, “Estudio y acción”: 549-551.

${ }^{67}$ Carrillo-Linares, Subversivos y malditos: 285-370; Jordi Sancho Galán, "Hacia el estado de excepción. Radicalización estudiantil y represión en la Universidad de Barcelona (19681969)," X Encuentro de Investigadoras e Investigadores del Franquismo, (Valencia: Universidad de Valencia, 2019).
} 
versidades en el año 1974. Ese tema, junto a la imposición de la selectividad y la lucha de los profesores no numerarios, concentró la atención de todas las organizaciones y asociaciones estudiantiles en sus órganos de comunicación. En ese sentido, encontramos otro punto común con las revistas estudiantiles argentinas bajo la dictadura en relación a la centralidad creciente de la agenda gremial propia de la vida estudiantil entre las reivindicaciones estudiantiles en el marco de las transiciones y como claves para la construcción de un modelo de universidad democrática: autónoma, sin selectividad en el ingreso, con libertad de asociación estudiantil y participación del alumnado en el gobierno de las instituciones ${ }^{68}$.

\section{A modo de cierre}

En el presente artículo, proponemos una caracterización general de las experiencias editoriales de los estudiantes universitarios de España y Argentina bajo dictaduras y algunas claves comparativas en relación con las modalidades en que surgieron y cómo se fueron reconfigurando dichos proyectos editoriales respecto de sus posturas hacia el régimen y del desarrollo del movimiento estudiantil de cada país.

Hemos dado cuenta de un fenómeno relevante en ambos casos nacionales, escasamente abordado, sobre todo en Argentina. En ambos países, en un marco de represión a la militancia estudiantil universitaria, la elaboración y distribución de publicaciones específicamente estudiantiles fue una estrategia compartida por las agrupaciones estudiantiles que no acordaban con el régimen. Identificamos matices respectos a las modalidades en que las revistas fueron presentadas al estudiantado, en Argentina bajo "camuflaje" de revistas científicas o meramente gremiales sin identidad política definidas, en España, también se publicaron como órganos de comunicación de agrupaciones políticas, asociaciones estudiantiles, comités, que cuestionaban al SEU y la dictadura franquista abiertamente. En ese sentido, es posible pensar que estas publicaciones "desde abajo" funcionaron, en mayor medida, como espacios de resistencia en busca de la caída del régimen tal como lo propone Müller para el caso de Brasil ${ }^{69}$. Este matiz, consideramos, puede estar relacionado con los ciclos globales de movilización estudiantil. Mientras

${ }^{68}$ Carrillo-Linares, "Universidades y transiciones políticas”; Seia, "El movimiento estudiantil contra la política universitaria".

${ }^{69}$ Angélica Müller, O movimiento estudiantil na Resistencia a ditadura militar (1969-1979). 
que en España el alumnado anti-franquista se suma la ola de movilización estudiantil de los sesentas y los tempranos setentas, en Argentina la reorganización del movimiento estudiantil se da en el marco de la imposición de las dictaduras de la Doctrina de Seguridad Nacional en todo el Cono Sur americano y en una etapa de desmovilización y des-radicalización política a nivel internacional ${ }^{70}$. Al respecto surgen dos reflexiones complementarias. La primera acerca de la importancia de la prensa en contextos disímiles respecto de los niveles de movilización y también de represión, y la segunda, relativa a la necesidad de pensar en periodizaciones más amplias para continuar profundizando la investigación comparativa a nivel iberoamericano.

Aunque con importantes puntos de contraste, también la elaboración y distribución de prensa por parte de sectores afines a las autoridades tuvo importancia en ambos casos considerados. En tanto la comparación permite re-pensar las categorías de análisis, hemos puesto en cuestión la potencia de la idea de revistas "desde arriba" para el caso español al dar cuenta de la complejidad del fenómeno de las revistas del SEU a lo largo de casi tres décadas de producción y circulación. Nuevamente, el ciclo político más general tiene un peso importante para analizar los debates, los cuestionamientos y los desplazamientos hacia la izquierda del alumnado que inició su socialización política en el marco de las actividades del sindicato. De todos modos, en ambos casos hemos visto como las iniciativas oficiales hacia el estudiantado funcionaron también como espacios para el debate y la construcción de posicionamientos no oficialistas.

Del presente desarrollo se desprende la posibilidad de identificar en ambos casos diferentes sub-etapas y tipos de producción editorial estudiantil, incluso cuando la dictadura argentina fue mucho más breve. Las publicaciones en ambos países modificaron sus contenidos y formatos en función de la coyuntura política y/o universitaria de cada caso, expresando preocupaciones, reivindicaciones, humores sociales, formas de organización y debates al interior del movimiento estudiantil, la izquierda y del alumnado en general. Para el caso español es central considerar el contexto local de surgimiento y circulación de la publicación, atendiendo a las particularidades políticas, geográficas, sociales de cada región. Estas dos últimas variables suman complejidad al objeto de estudio en tanto la dictadura franquista se extendió por más de tres décadas y al interior de España nos encontramos con publicaciones estudiantiles no sólo de diferentes universidades, carreras,

${ }^{70}$ Colin Barker, "Some Reflections on Student Movements of the 1960s and Early 1970s," Revista Crítica de Ciências Sociais, n. 81 (2008): 43-91. 
organizaciones políticas y/o estudiantiles sino también escritas en diversas lenguas, atendiendo a problemáticas locales específicas.

Como se observa, aún quedan muchos aspectos a considerar en la construcción de investigaciones comparativas y también transnacionales, resta indagar un aspecto tan importante como la construcción de solidaridades internacionales entre los movimientos estudiantiles y las izquierdas de España y América Latina durante la segunda mitad del siglo XX, que consideramos las revistas posibilitarán reconstruir.

\section{Bibliografía}

Alonso, Luciano. "Dictaduras regresivas y represiones en Iberoamérica: trayectorias particulares y posibilidades de comparación". En Procesos represivos y actitudes sociales: entre la España franquista y las dictaduras del Cono Sur, editado por Gabriela Águila y Luciano Alonso. Buenos Aires: Prometeo, 2013.

Aróstegui, Julio. Historia y memoria de la Guerra Civil: encuentro en Castilla y León: Salamanca, 24-27 de Septiembre de 1986. Prensa juvenil y estudiantil durante la guerra civil (1936-1939): caracterización y catalogación. Valladolid: Junta de Castilla y León, 1988.

BARKer, Colin. "Some Reflections on Student Movements of the 1960s and Early 1970s". Revista Crítica de Ciências Sociais, n. 81 (2008): 43-91.

BERguiER, RubÉn; EdUARdo HECKER y ARIEL SCHIFRIN. Estudiantes secundarios: sociedad y política. Buenos Aires: CEAL, 1986.

Bohoslavsky, ERnesto. "Introducción al Dossier: América Latina (19501989): perspectivas desde la historia comparada". En Quinto Sol, v. 19, n. 1 (2015): 1-3.

BRUNNER, JOAQUín. "El movimiento estudiantil ha muerto. Nacen los movimientos estudiantiles". En Material de discusión FLACSO, n. 71 (1985): $\mathrm{s} / \mathrm{p}$.

BuchBinder, PABlo. "La Universidad de Buenos Aires bajo la dictadura. Una aproximación a través del estudio del perfil, discurso y pronunciamientos públicos de dos de sus rectores." CIAN-Revista de Historia de las Universidades, 19/2 (2016): 153-173.

Bustelo, Natalia. "La Reforma Universitaria desde sus grupos y revistas: Una reconstrucción de los proyectos y las disputas del movimiento estudiantil porteño de las primeras décadas del siglo XX (1914-1928)." Tesis doctoral, UNLP, 2015. 
Carreño, LuCiana. "La Federación Universitaria Hispanoamericana en Madrid". En CIAN-Revista de Historia de las Universidades, v. 16 n.1 (2013): 51-80.

CARRILlo-Linares, AlBerto. Subversivos y malditos en la Universidad de Sevilla (1965-1977). Sevilla: Centro de Estudios Andaluces, 2008.

Carrillo-Linares, Alberto. "Universidades y transiciones políticas: el caso español en los años 60-70". Espacio, Tiempo y Educación, n. 2, v. 2 (2015): 49-75.

ERrazuriz TAGLE, JAVIERA. "Movimiento estudiantil en el tránsito de dictadura a democracia. Madrid (1969-1980) y Santiago de Chile (1986-1997) en perspectiva comparada". Tesis de Doctorado, UCC-UAM, 2013.

FRANCO, MARINA. El final del silencio, Dictadura, sociedad y derechos humanos en la transición (Argentina, 1979-1983). Buenos Aires: FCE, 2018.

García Monge, Diego; José Isla Madariaga y Pablo Toro Blanco. Los muchachos de antes. Historias de la FECH 1973-1988. Santiago: Universidad Alberto Hurtado, 2006.

GARcía, JoRDI. Estado y cultura: el despertar de una conciencia crítica bajo el franquismo, 1940-1962. Barcelona: Anagrama, 2006.

GONZÁLEZ GóMEZ, SARA. "Prensa universitaria salamantina durante la segunda mitad del franquismo". En La prensa de los escolares y estudiantes, editado por José Hernández Díaz. Salamanca: Ed. Universidad de Salamanca, 2015.

GonzÁlez VAILlant, Gabriela. "Entre los intersticios de la democracia. Las revistas estudiantiles, la universidad uruguaya en transición y las pujas políticas por los significados de la democracia". En Revista de Historia Social y de las Mentalidades, v.22, n. 2 (2018): 73-102.

HAUPT, HEINZ Y JÜRGEN KocKA. "Comparison and Beyond: Traditions, Scope, and Perspectives of Comparative History". En Comparative and transnational history. Central European Approaches and New Perspectives, editado por Heinz Haupt y Jürgen Kocka. New York-Oxford: Bergham Book, 2009.

HERNÁNDEZ DíAZ, JosÉ. "La prensa de los estudiantes en España. Justificación pedagógica y tipología”. En La prensa de los escolares y estudiantes: $\mathrm{Su}$ contribución al patrimonio histórico educativo, editado por José Hernández Díaz. Salamanca: Ed. Universidad de Salamanca, 2015.

HeRnández Sandoica, Elena; Miguel Ángel Ruiz Carnicer y MaRc Baldó LACOMBA. Estudiantes contra Franco (1939-1975). Oposición política y movilización juvenil. Madrid: La esfera de los libros, 2007. 
IGLESIAS, FEDERICO. Escritores, dictadura y resistencia: un estudio sobre la revista El Ornitorrinco 1977-1983. Los Polvorines: UNGS-UNLP-UNAM, 2019.

LASTRA, SOLEDAD. "La historia comparada y sus desafíos para interrogar el pasado reciente del Cono Sur". En Revista de Historia Comparada, v.12, n. 2 (2018): 139-171.

LUCIANI, LAURA. Juventud en dictadura: representaciones, políticas y experiencias juveniles en Rosario: 1976-1983. La Plata: UNLP-UNAM-UNGS, 2017.

LVOVICH, DANIEL. "Actitudes sociales y dictaduras: las historiografías española y argentina en perspectiva comparada". En Procesos represivos y actitudes sociales: entre la España franquista y las dictaduras del Cono Sur, editado por Gabriela Águila y Luciano Alonso. Buenos Aires: Prometeo, 2013.

Malmierca, Raúl. "Prensa estudiantil clandestina en la Universidad de Salamanca. La publicación de Acción durante el tardofranquismo en Salamanca (1969-1976)". En La prensa de los escolares y estudiantes, editado por José Hernández Díaz. Salamanca: Ed. Universidad de Salamanca, 2015.

MANCEBo, Fernanda y Josep Vivó. "Análisis temático de la prensa de las asociaciones estudiantiles (publicaciones de la UFEH-FUE y la FNEC)". En Historia y memoria de la Guerra Civil, editado por Julio Aróstegui. Valladolid: Junta de Castilla y León, 1988.

Manzano, VAleria. La era de la juventud, Cultura, política y sexualidad desde Perón hasta Videla. Buenos Aires: FCE, 2017.

MARGIOLAKIS, EvANGELINA. "La conformación de una trama colectiva de publicaciones culturales subterráneas durante la última dictadura cívicomilitar". Contenciosa, v. 2, n. 2 (2016): 1-13.

Millán MaRiano y GuAdaluPe Seia. "El movimiento estudiantil como sujeto de conflicto social en Argentina (1871-2019). Apuntes para una mirada de larga duración". En Entramados y Perspectivas, v. 9, n. 9 (2019): 125-167.

MinghetTI, NADiA. "La prensa estudiantil como táctica de resistencia a la dictadura. El caso de la revista Aristócratas del Saber en el Colegio Nacional de Buenos Aires." Tesis de Maestría, FLACSO, 2019.

MüLlER, ANGÉLICA. $O$ movimiento estudiantil na Resistencia a ditadura militar (1969-1979). Rio de Janeiro: Garamond, 2016.

Patto Sá MotTa, Rodrigo. Ditaduras militares. Brasil, Argentina, Chile e Uruguai. Belo Horizonte: Editora UFMG, 2015. 
Polak, LaURa y JUAN Gorbier. El movimiento estudiantil Argentino (Franja Morada 1976-1986). Buenos Aires: CEAL, 1994.

Rodríguez LóPEz, CAROLINA. "La universidad europea bajo las dictaduras". En Ayer, n. 101 (2006).

Rodríguez LóPEz, CARolina. La Universidad de Madrid en el primer franquismo: ruptura y continuidad (1939-1951). Madrid: Editorial Dykinson/ Universidad Carlos III, 2002.

Rodríguez Tejada, Sergio. Zonas de libertad. Dictadura franquista y movimiento estudiantil en la Universidad de Valencia. Vol. I (1939-1965). Valencia: Publicaciones de la Universidad, 2009.

RODRÍGUEZ, LAURA. "Los estudiantes reformistas y su proyección latinoamericana: los congresos internacionales (1921-1957)". En Revista del IICE, n. 44 (2018): 11-24.

RODRíGUEZ, LAURA. Universidad, peronismo y dictadura. 1973-1983. Buenos Aires: Prometeo, 2015.

Rubio Mayoral, Juan Luis y Guadalupe Tringueros Gordillo. "Estudio y acción. Información, propaganda política e ideología en la prensa universitaria hispana (1939-1968)". En La prensa de los escolares y estudiantes, editado por José Hernández Díaz. Salamanca: Ed. Universidad de Salamanca, 2015.

Ruiz CARNiCER, Miguel ÁNGEL. "Jóvenes, intelectuales y falangistas: apuntes sobre el proceso de ruptura con la dictadura en los años sesenta". Cercles, n. 16 (2013): 103-122.

Ruiz Carnicer, Miguel Ángel. "La voz de la juventud. Prensa universitaria del SEU en el franquismo". Bulletin Hispanique, tomo 98, n. 1 (1996): 175-199.

SANChO Galán, JoRdi. "Hacia el estado de excepción. Radicalización estudiantil y represión en la Universidad de Barcelona (1968-1969)". X Encuentro de Investigadoras e Investigadores del Franquismo. Valencia, Universidad de Valencia, 2019.

SEIA, GuAdAluPE. "De la revolución a la reforma. Reconfiguraciones de las formas de militancia estudiantil en la Universidad de Buenos Aires entre 1976 y 1983." Tesis de Doctorado, UBA, 2019.

SEIA, GuAdALUPE. "El movimiento estudiantil contra la política universitaria de la última dictadura en Argentina. El caso de la Universidad de Buenos Aires". En Izquierdas, n. 49 (2020): 2213-2247.

SEIA, GUADALUPE. "El reformismo universitario entre la dictadura y la democracia. Un análisis del movimiento estudiantil de la UBA entre 1976 y 1983". En Cuadernos de Historia, n. 21 (2018): 166-191. 
Seia, Guadalupe. "Las Revistas Estudiantiles en la Universidad de Buenos Aires durante la última dictadura (1976-1983)". En La condición juvenil en Latinoamérica: identidades, culturas y movimientos estudiantiles, editado por Ivonne Meza Huacuja y Sergio Moreno Juárez. México: UNAM, 2019.

Suasnábar, Claudio. "Revista Perspectiva Universitaria. Voces disidentes en dictadura”. En Dictadura y Educación, editado por Carolina Kaufmann. Buenos Aires: Miño y Dávila, 2001.

Toro Blanco, Pablo. "Entre la lana y el gel: notas sobre opciones y estilos artísticos y culturales del movimiento estudiantil en la Universidad de Chile (ca. 1977- ca. 1990)". En Movimientos estudiantiles en la historia de América Latina, editado por Renate Marsiske. México: UNAM, 2017.

VARela GonzÁlez, Isaura y Miguel Ángel Ruiz CARnicer. "Prensa juvenil y estudiantil en el bando franquista durante la guerra civil (1936-1939)". En Historia y memoria de la Guerra Civil, editado por Julio Aróstegui. Valladolid: Junta de Castilla y León, 1988. 